\title{
Dinâmica de prazer e sofrimento de estudantes negras de faculdades de Brasília - Epistemicídio, racismo e machismo
}

\author{
Pleasure and suffering dynamics in black female \\ students from universities in Brasilia- Epistemicide, \\ racism and machismo

\section{Dinámica de placer y sufrimiento de estudiantes racismo y machismo} \\ negras de universidades de Brasilia- Epistemicidio,
}

\author{
Flávia Oliveira* \\ Tayane Nunes** \\ Carla Antloga $a^{* * *}$
}

\begin{abstract}
Resumo
O crescente acesso de mulheres negras à educação superior no Brasil ainda não permitiu suplantar as desigualdades, a população branca ainda é duas vezes maior que a população negra nesses espaços. Neste contexto, os estudos que investigam a relação da mulher negra com o trabalho de estudar são incipientes. $O$ presente artigo teve como objetivo identificar, sob a ótica da psicodinâmica do trabalho, a dinâmica de prazer e sofrimento e as estratégias de mediação de estudantes negras de graduação. Foram realizadas entrevistas semiestruturadas com 8 mulheres estudantes de graduação que se identificaram como negras, com média de idade 21,62 anos e DP =2,82. Por meio de análise no software Iramuteq, foram identificadas categorias a

Mestranda pelo programa de pós-graduação em psicologia clínica e cultura pela Universidade de Brasília. E-mail: flavia.ogm@gmail.com

** Aluna de graduação em psicologia pela Universidade de Brasília. E-mail: nunes.tng@

*** Programa de Pós-Graduação em Psicologia Clínica e Cultura da Universidade de Brasília. E-mail: antlogacarla@gmail.com
\end{abstract} gmail.com 
respeito da vivência dessas mulheres negras, sendo elas sua rede de suporte, a ocupação do espaço universitário, sua rotina acadêmica e as experiências com os racismos sofridos. A partir dessas categorias, foi possível identificar: o epistemicídio e racismo institucional que ocorrem quando a presença na universidade e conhecimentos da população negra não são legitimados; a importância da valorização e do reconhecimento dos familiares e a potencialidade de se engajar em mobilização subjetiva e coletiva por meio da ocupação de espaços públicos e cooperação entre pares.

Palavras-chave: Psicodinâmica do trabalho, mulher negra, educação superior, gênero, raça

\section{Abstract}

The increasing access of black women to higher education in Brazil has not yet led to the end of inequality. The white population is still three times larger than the black population in this area. In this context, studies that investigate the relationship between black women and academia are incipient. The present article aimed to identify, from the perspective of work psychodynamics, the dynamics of pleasure and suffering and the mediation strategies of undergraduate black students. Semi-structured interviews were conducted in 8 undergraduate women who identified themselves as black, with an average age of 21.62 years and $S D=2.82$. Through analysis in the Iramuteq software, categories were identified regarding the experience of these black women, being their network of support, the occupation of the university space, their academic routine and the experiences with the racisms suffered. From these categories, it was possible to identify: the epistemicide and institutional racism that occur when the presence in the university and knowledge of the black population are not legitimized; the importance of appreciation and recognition of family members and the potential for engaging in subjective and collective mobilization through the use of public spaces and peer cooperation.

Keywords: Work Psychodynamics, black women, higher education, gender, race

\section{Resumen}

El acceso cresciente de mujeres negras a la educación superior en Brasil aún no ha permitido suplantar las desigualdades, la población blanca aún es trés vezes mayor que la población negra en estos espacios. En este contexto, los estudios que investigan la relación de la mujer negra con el trabajo que significa estudiar, son incipientes. El presente artículo tuvo como objectivo identificar, bajo la óptica de la psicodinámica del trabajo, la dinámica de placer y sufrimiento, y las estrategias de mediación de estudiantes negras de pregrado. Se realizaron entrevistas semiestructuradas en ocho mujeres estudiantes de pregrado que se identificaron como negras, con edad promedio de 21,62 años $(D T=2,82)$. 
Por medio de análisis en el software Iramuteq, se identificaron categorias acerca de la viviencia de estas mujeres negras, sendo ellas su red de apoyo, la ocupación del espacio universitario, su rutina académica y las experiencias con lo racismo sufrido. A partir de esas categorias, ha sido possible identificar: el epistemicidio y racismo institucional que ocurren cuando la presencia en la universidad y los conocimientos de la población negra no son legitimados, la importancia de la valoración y del reconocimiento de familiares y la potencialidad de involucrarse en mobilización subjetiva y colectiva por medio de la ocupación de espacios públicos y cooperación entre pares.

Palabras clave: Psicodinámica del trabajo, mujeres negras, educación superior, género, raza

O ponto de partida deste estudo foi a fala de uma estudante negra no corredor da universidade a que são filiadas as autoras: "Para uma mulher negra, estudar é um trabalho tão desgraçado como qualquer outro dos que estão separados pra gente...”. A fala, tão espontânea e tão profunda, levou-nos às questões que nortearam este estudo: 1. Estudar é trabalho?; 2. Quais dificuldades as estudantes negras enfrentam para estudar?; 3. Como o trabalho de estudar se articula de maneira a promover o mal-estar declarado pela estudante?

A concepção moderna de trabalho está atrelada à de emprego (Woleck, 2002). Todavia, do ponto de vista prático e teórico, trabalho e emprego são categorias distintas, a despeito de, na linguagem do senso comum, serem utilizadas como sinônimos.

Muitas atividades que não ocorrem como "emprego" deixam de ser consideradas trabalho (Kergoat, 2016) e, assim, deixam também de ser objeto de estudo das próprias ciências do trabalho. Um exemplo disto é a atividade de estudar, um dos maiores símbolos de como o ser humano pode ser modificado pela atividade que realiza: os estudantes estão em um constante processo de desenvolvimento, ganho de novas habilidades e se preparando permanentemente para transformar a "natureza". Se o homem forja o trabalho, e o trabalho "forja" o homem (Ferreira, 2003), a atividade de estudar é o maior exemplo de como um trabalho "forja" um indivíduo. Assim, de entrada, defendemos que estudar é uma forma de trabalho.

Estudar é uma atividade programada, da qual são esperados resultados pelos investimentos físico, cognitivo, temporal e afetivo, tal como no 
trabalho. Neste sentido, é impossível diferenciar se uma atividade é trabalho ou não apenas com base na formalidade de um vínculo empregatício ou em remuneração. Ainda que este fosse o caso, há possibilidade do pagamento de bolsas a estudantes, que desenvolvem vínculo institucional (ainda que não tenha, formalmente, o caráter de vínculo empregatício). Sendo assim, não há distinção perceptível dos investimentos alocados para o trabalhar e para o estudar.

Para investigar o processo psicodinâmico de vivências de prazer e/ou de sofrimento das estudantes negras, bem como as estratégias de mediação desenvolvidas, este estudo se apoia na psicodinâmica do trabalho (Dejours, 2004). Além disso, apoiamo-nos na teoria da consubstancialidade (Guimarães, 2016), que trata da origem do cruzamento das relações de poder, postulando que não há maneira de separar as diferentes formas de opressão. Isso implica dizer que essas questões não seguem uma lógica puramente aditiva e inter-relacional, mas que estão imbricadas e, portanto, não é possível analisar uma separada da outra (Guimarães, 2016).

Como via de construção da subjetividade, o trabalho está entrelaçado com outros fatores estruturantes da organização social, como raça, classe e gênero. O modelo de sociedade patriarcal em que vivemos, que se desenvolveu em um cenário colonial e racista, faz com que especialmente a divisão social do trabalho reflita tais relações de poder. Há diversas vias pelas quais as relações de trabalho servem como formas de manutenção e reprodução de violências contra minorias políticas como pessoas negras, mulheres, população de baixa-renda, desempregados, etc. (Xavier \& Fontoura, 2013). No caso do trabalho de estudar, por exemplo, até há pouco não era uma atividade para mulheres e menos ainda para mulheres negras (Davis, 2016).

Podemos pensar na articulação da violência do trabalho destinado para as negras com a ousadia de querer estudar. Se o trabalho de estudar for “desgraçado”, pouco importa. Afinal, para a mulher negra, estão destinados os trabalhos mais sofridos. Experimentar muito sofrimento no trabalho de estudar está dentro do previsto para estas mulheres.

O reconhecimento da precariedade das condições vivenciadas por negras no mercado de trabalho brasileiro aponta que o trabalho frequentemente é analisado somente pela perspectiva das questões de gênero, como 
apontado por Bento (1995). A autora critica o não aprofundamento dos estudos de trabalho em questões raciais e de gênero, de maneira que não se pode ir além da costumeira constatação "no caso das Mulheres Negras essa situação é mais dramática” (p.479). De fato o é e faz-se necessário compreender que, para as que podem estudar, o drama já existente se intensifica neste contexto.

A análise desarticulada que é feita quanto aos dados de gênero e raça, se repete nos dados sobre educação. Apesar de ser evidente que há precariedade quanto à inserção de negros na educação superior no Brasil, são poucas as análises com recortes simultâneos de gênero e raça. Tal fato, segundo Reichman (1995), invisibiliza o racismo e as especificidades das mulheres negras. Ainda hoje, mais de 20 anos depois do estudo de Reichman, as estatísticas oficiais pouco evidenciam a consubstancialidade de gênero e raça. A ausência de dados sobre esses fatores mascara diferenças entre mulheres negras e o restante da população, o que dificulta a elaboração de políticas públicas que possam promover equidade e oportunidade de crescimento para essas mulheres.

Com as estatísticas disponíveis, identifica-se que, em linhas gerais, apesar de uma considerável diminuição da disparidade do Censo IBGE (Brasil, 2012) e o PNAD Contínua - Educação (2017), o acesso à educação é majoritariamente da população branca. Segundo os dados apresentados as taxas ajustadas de frequência escolar líquida ao ensino superior, que se refere à permanência dos alunos neste espaço, apontam que, em 2017, $32,9 \%$ da população branca se encontra nesta etapa da educação, enquanto 16,7\% da população preta ou parda. Ou seja, nas instituições de nível superior, a população branca é, aproximadamente, o dobro da população negra. Além disso, o estudo também aponta esta taxa de frequência segundo o sexo, onde, em 2017, 19,7\% dos homens frequentam o ensino superior, enquanto 26,8\% das mulheres frequentam este espaço.

Apesar do PNAD tratar raça e gênero separadamente, é mister analisar a consubstancialidade dessas categorias. Tem-se como exemplo o processo histórico de exploração do trabalho doméstico de mulheres negras para inserção das mulheres brancas no mercado de trabalho formal (Gonzalez, 1984). A exploração da força produtiva de trabalho de mulheres 
negras estabelece-se em prol do exercício de um poder opressivo que mantém as hierarquias sociais vigentes. Sob efeito deste modelo colonialista, as categorias analíticas referentes à raça, classe e gênero, foco deste estudo, estabelecem-se de modo central nos processos exclusão, simbólicos e materiais, desses indivíduos em determinados espaços da sociedade.

O colonialismo, para além de todas as dominações por que é conhecido, foi também uma dominação epistemológica, uma relação extremamente desigual de saber-poder que conduziu à supressão de muitas formas de saber próprias dos povos e nações colonizados, relegando muitos outros saberes para um espaço de subalternidade (Santos \& Meneses, 2010, p. 7).

Sueli Carneiro comenta que o epistemicídio, a partir da sua definição como uma dominação epistemológica, "permite-nos tomá-lo para compreender as múltiplas formas em que se expressam as contradições vividas pelos negros com relação à educação e, sobretudo, as desigualdades raciais nesse campo.” (Carneiro, 2005, p.98). A eliminação deste grupo das instituições, bem como da sociedade, resulta na invisibilização da população negra e suas particularidades, bem como na falácia da democracia racial, que consiste na ideia de que não temos racismo no Brasil (Carneiro, 2011). O epistemicídio dificulta o acesso da população negra à educação, tornando esta população que é maioria, em termos quantitativos, minorizada nos espaços de representação e imaginário simbólico brasileiro (Santos, 2017).

Queiroz e Santos (2016) aponta que há um evidente esforço cotidiano da mulher negra para estar no ambiente acadêmico, pois, para elas, se trata de uma realidade aversiva e excludente na qual sua existência é desqualificada. Carneiro (2005) identifica um contexto generalizado de epistemicídio e que tais barreiras, sejam elas simbólicas ou concretas, dificultam a produção de conhecimento dessas mulheres. A médio e longo prazo, o epistemicídio interpõe-se de modo transgeracional num processo de retroalimentação. O reconhecimento de que estudantes negras defrontam-se com barreiras específicas no meio universitário, dificuldades essas associadas à aspectos estruturais de gênero, raça e classe, reforça a urgência de que sejam produzidos estudos que avaliem o trabalho de estudar de alunas negras. 
Para Bourdieu (1998), o ambiente educacional não necessariamente se configura como veículo de ascensão social das diferentes classes. Apesar de haver um entendimento generalizado que vê no sistema escolar um promotor de igualdade social, Bourdieu defende que a escola tem uma ação homogeneizante que termina por contribuir para aprofundar as desigualdades trazidas por cada educando ao longo de sua vida. De acordo com o autor:

É provável, por um efeito de inércia cultural que continuamos tomando o sistema escolar como um fato de mobilidade social segundo a ideologia da "escola libertadora, quando ao contrário, tudo tende a mostrar que ele é um dos fatores mais eficazes de conservação social, pois fornece a aparência de legitimidade às desigualdades sociais e sanciona a herança cultural e o dom social e dom natural. (p.41)

Há uma carência de pesquisas na área de psicodinâmica do trabalho que abordam as categorias analíticas de gênero e raça (Zanello, 2018) e, por óbvio, uma abordagem que se propõe a estar do lado daqueles que vivem do trabalho no dilema capital-trabalho, e que reconheça as especificidades dessa parcela mais oprimida entre os trabalhadores, precisa voltar seu olhar para essas questões.

Para a psicodinâmica do trabalho, a vivência do prazer está associada à liberdade e reconhecimento, ao passo que o sofrimento está atrelado à precarização dessas vivências, bem como a impossibilidade de se defender dos aspectos negativos do trabalho (Mendes, 2007). Ainda que o contexto de trabalho seja de precarização, é possível o trabalhador vivenciar o prazer se, em sua realidade de trabalho, ele conseguir desenvolver estratégias que possibilitem a ressignificação do sofrimento. Desde que a organização possibilite ao trabalhador um espaço de construção livre e criativa de ações mobilizadoras, há possibilidade de que o sofrimento se transforme em prazer (Ferreira \& Mendes, 2003, Dejours, 2016).

Assim, considerando a necessidade da psicodinâmica do trabalho avançar quantos às questões de gênero e raça e considerando ainda os apontamentos sobre desigualdade no ensino superior, racismo institucional e desvalorização do trabalho das mulheres negras, o objetivo do presente 
estudo é identificar, sob a ótica da psicodinâmica do trabalho, a dinâmica de prazer e sofrimento e as estratégias de mediação que estudantes negras de faculdades de Brasília desenvolvem para lidar com a consubstancialidade das adversidades que enfrentam no trabalho de estudar.

\section{MÉTODO}

\section{Participantes}

Em concordância com o objetivo do presente estudo, definiu-se como público-alvo mulheres estudantes de graduação que se identificaram como negras. Foram recrutadas por meio de divulgação da pesquisa em redes sociais no período de 08/05/2017 a 08/07/2017. Ao todo, foram entrevistadas 8 mulheres, com média de idade entre 18 e 27 anos (média: 21,62, $\mathrm{DP}=2,82)$. Destas, sete estudavam em universidade pública e uma em faculdade particular, estando todas matriculadas em cursos na área de ciências humanas e sociais. No momento desta coleta de dados, todas eram moradoras do DF, com renda familiar entre $\mathrm{R} \$ 996,00$ e $\mathrm{R} \$ 10.000,00$ (média $\mathrm{R} \$ 4.862,12$ e $\mathrm{DP}=\mathrm{R} \$ 3.215,09$ ).

\section{Instrumento e coleta de dados}

Para a coleta de dados, utilizou-se como instrumento um roteiro de entrevista semiestruturado com questões sobre: 1) a vivência de ser negra e estudante de graduação; 2) percepções sobre diferenças de tratamento e dificuldades, em relação à aspectos de raça e gênero, encontradas no espaço acadêmico; 3) Formas de enfrentamento às dificuldades vivenciadas no trabalho de estudar; 4) Redes de apoio e fatores de proteção. $\mathrm{O}$ acesso às participantes da pesquisa se deu por meio da divulgação em redes sociais (Facebook e Whatsapp) de um formulário online (Google Forms). Este documento, além de apresentar os objetivos do estudo, solicitava dados de contato para agendamento de entrevistas presenciais. Antes da realização da entrevista, apresentou-se o Termo de Consentimento Livre e Esclarecido 
(TCLE), documento que continha informações sobre os objetivos do estudo, seu caráter voluntário e confidencial, e que solicitava autorização para gravações de áudio.

\section{Análise de Dados}

Para a análise de dados, utilizou-se o software de análise lexical Interface de $R$ pour les Analyses Multidimensionnelles de Textes et de Questionnaires - IRAMUTEQ, versão 0.7 (Ratinaud, 2009). Esse software, com as entrevistas agrupadas e organizadas em forma de corpus textual, é capaz de realizar diferentes análises textuais. Entre as possibilidades de análise, a utilizada no presente artigo foi o método classificação hierárquica descendente - CHD (Camargo \& Justo, 2013). Tal análise classifica as dimensões subjacentes ao texto e a sua importância para explicação do mesmo. Com os resultados obtidos, fez-se uma análise das falas das entrevistadas à luz da teoria da psicodinâmica do trabalho.

\section{RESULTADOS E DISCUSSÃO}

As análises do Iramuteq revelaram o agrupamento de quatro classes que representam as categorias presentes na fala das entrevistadas, conforme a Figura 01. A classe 1 foi denominada como "Rede de suporte" e compreende a vinculação a pessoas ou grupo de pessoas disponíveis para acolhimento e apoio em meio a sofrimentos vivenciados no meio acadêmico. A classe 2, "Ocupação do espaço universitário", compreende percepções em torno das representações e simbolismos sobre ser negra e estudante de graduação, assim como obstáculos enfrentados para ocupar este lugar. A classe 3, "Rotina acadêmica", traz descrições sobre a rotina do trabalho de estudar. A classe 4, "Experiências com racismo", abarca a identificação de vivências de opressão racial no espaço acadêmico. 


\begin{tabular}{|c|c|c|c|c|c|c|c|c|c|c|c|}
\hline \multicolumn{3}{|c|}{ Classe 1- Redes de Suporte 32,5\% } & \multicolumn{3}{|c|}{$\begin{array}{c}\text { Classe 2- Ocupas bo do Espaço } \\
\text { Universitario 21, } 7 \%\end{array}$} & \multicolumn{3}{|c|}{ Classe 3 - Rotina Academica 18,3\% } & \multicolumn{3}{|c|}{$\begin{array}{l}\text { Classe } 4 \text { - Experiencias com Racismo } \\
\qquad 27,6 \%\end{array}$} \\
\hline Forma & $x^{2}$ & $p$ & Forma & $x^{2}$ & $p$ & forma & $x^{2}$ & $D$ & Forma & $x^{2}$ & $p$ \\
\hline muito & 53,67 & 4,0001 & escola & 38,21 & $<0,0001$ & ler & 138,71 & $\infty, 0001$ & espaso & 85,12 & $\propto, 0001$ \\
\hline psi & 41,95 & 4,0001 & comesar & 36,96 & 40,0001 & texto & 114,66 & $\infty, 0001$ & raxismo & 43,76 & $\infty, 0001$ \\
\hline mbe & 31,39 & 4,0001 & ano & 36,83 & $\ll, 0001$ & aula & 105,4 & $\infty, 0001$ & realidade & 37,22 & $\infty, 0001$ \\
\hline bom & 25,91 & 0,0001 & faculdade & 35,03 & $<0,0001$ & matéria & 81,7 & $\infty, 0001$ & mulher & 37,22 & $\$, 0001$ \\
\hline nim & 20,27 & $\infty, 0001$ & sair & 33,42 & $<0,0001$ & professor & 20,97 & $\infty, 0001$ & maneira & 32,99 & $\infty, 0001$ \\
\hline dar & 18,91 & $\$, 0001$ & ensino & 31,39 & 40,0001 & sala & 55,21 & $-0,0001$ & ratista & 31,88 & $\propto 0,001$ \\
\hline cass & 18,37 & 4,0001 & médio & 30,49 & $<0,0001$ & prova & 54,18 & $\infty, 0001$ & pessos & 30,47 & $<0,0001$ \\
\hline famtia & 18,14 & $<, 0001$ & $\begin{array}{l}\text { Centro_universitári } \\
\text { o_de_Brashia }\end{array}$ & 29,13 & $<0,0001$ & pegar & 45,7 & $\infty, 0001$ & trazer & 29,26 & $<, 0001$ \\
\hline ditiol & 16,79 & $\infty, 0001$ & pensar & 27,61 & $<0,0001$ & geralmente & 34,7 & 0,0001 & ndo & 28,31 & $\infty, 0001$ \\
\hline tempo & 16,62 & $\infty, 0001$ & pedrgogia & 27,18 & 4,0001 & chamado & 26,93 & $\infty, 0001$ & privilégio & 27,84 & $\infty, 0001$ \\
\hline entender & 16,04 & $\infty, 0001$ & serio & 25,47 & 40,0001 & prestar & 25,7 & $\$ 0,001$ & algo & 26 & $\infty, 0001$ \\
\hline sentar & 14,76 & 0,00012 & psicologia & 24,7 & $<0,0001$ & ementa & 22,83 & $\$ 0,0001$ & talvez & 25,46 & $\propto 0,001$ \\
\hline ficar & 13,83 & 0,0002 & beleza & 24,16 & $\infty, 0001$ & atensăo & 22,83 & $\infty, 0001$ & expressso & 23,87 & $\infty, 0001$ \\
\hline morar & 13,41 & 0,00025 & vestibula & 24,16 & $\infty, 0001$ & trote & 22,42 & $\infty, 0001$ & errado & 23,87 & $\infty, 0001$ \\
\hline tio & 13,18 & 0,00028 & cabesa & 23,92 & $<, 0001$ & leitura & 22,42 & $\$ 0,0001$ & lado & 23,87 & $\propto 0,001$ \\
\hline virat & 13,18 & 0,00028 & terminar & 23,69 & $<0,0001$ & sociologia & 22.42 & $\infty, 0001$ & ver & 23,79 & $\infty, 0001$ \\
\hline sentir & 12,45 & 0,00041 & formar & 20,69 & $<0,0001$ & raza & 22,0 & 20,0001 & principalmente & 22,36 & $\infty, 0001$ \\
\hline dinheiro & 11.59 & 0,00066 & quando & 20,52 & $<0,0001$ & pesado & 22,02 & $\$ 0,0001$ & expressar & 22,36 & $\propto 0,001$ \\
\hline conversa & 11,46 & 0,00071 & entrar & 18,58 & $<0,0001$ & pergunta & 21,42 & $\infty, 0001$ & diversidade & 21,2 & $\infty, 0001$ \\
\hline amigo & 10,87 & 0,00097 & considerā̧̧o & 18,15 & $\$ 0,0001$ & mestrado & 21,42 & $\infty 0,0001$ & conseguir & 20,97 & $\& 0,001$ \\
\hline embora & 10,45 & 0,00122 & pagar & 17,54 & $<0,0001$ & autor & 20,06 & $+0,0001$ & luta & 19,73 & $<0,0001$ \\
\hline apoiar & 10,45 & 0,00122 & radal & 17,02 & $<0,0001$ & forma & 18,36 & $\infty, 0001$ & aberta & 19,73 & $<, 0001$ \\
\hline estava & 10,41 & 0,00125 & quase & 15,18 & $<, 0001$ & carga & 17,92 & $\infty, 0001$ & mulher_negra & 19,57 & $\infty, 0001$ \\
\hline coisa & 10,02 & 0,00155 & & & & presença & 17,92 & $\infty 0,0001$ & olhar & 18,69 & $\infty, 0001$ \\
\hline \multirow[t]{3}{*}{ mal } & 10,02 & $0,0015 s$ & & & & paciência & 17,92 & $థ 0,0001$ & empatis & 16,4 & $<0,0001$ \\
\hline & & & & & & teórice & 17,92 & $\$ 0,0001$ & nomem & 16.4 & $\ll, 0001$ \\
\hline & & & & & & fichamento & 17,92 & 40,0001 & homem_branco & 15,87 & $\infty, 0001$ \\
\hline
\end{tabular}

Figura 1 - Classificação hierárquica descendente obtida a partir da transcrição das falas das entrevistadas e relação entre as categorias.

A figura 1 também apresenta a relação entre essas categorias. Ao examinar a estrutura das classes em conjunto com o corpus textual obtido por meio das falas das entrevistadas, foi possível determinar o tema de cada classe. As linhas que conectam uma classe a outra indicam que as classes 1, 2 e 3 apresentam uma relação mais próxima e que a classe 4 se liga a todas elas. Isso implica dizer que as entrevistadas identificam que diferentes formas de racismo tanto configuram sua percepção sobre o espaço que ocupam na academia, quanto afeta as possibilidades de construção de rede de apoio.

As categorias de análise apontadas pelo Iramuteq são indissociáveis. Assim, tem-se o fato de que a necessidade de recorrer a uma rede de suporte (classe 1) está associada a identificação de racismo institucional (classe 4) que se dá por meio de barreiras materiais e simbólicas a presença destas alunas no espaço acadêmico (classe 2) assim como nas rotinas do trabalho de estudar (classe 3). Dos relatos das entrevistadas, depreende-se que a rede de apoio constitui-se majoritariamente por familiares, amigos e coletivos 
formados por pessoas negras, sem que estas reconheçam tal disponibilidade na instituição, conforme explicitado na fala da Participante Luísa Mahin:

Eu procuro [apoio] muito mais dentro de casa porque lá foi a minha base e a minha base é um tanto à frente do que que a gente está vivendo hoje, porque lá eu já tinha debate [sobre questões raciais] (Participante Luísa Mahin)

A fala dessas estudantes mostra que elas buscam apoio em quem valida sua percepção de racismo e reconhece como ele afeta sua vida pessoal e acadêmica. Observa-se também que todos os coletivos elencados por elas não eram de origem institucional, ou seja, elas não identificam apoio da instituição que esteja de acordo com as suas vivências negras e políticas de equidade racial. Neste sentido, a instituição viabiliza a entrada das negras em seu espaço, mas as estudantes não reconhecem políticas que auxiliem na sua permanência e no seu bem-estar, o que influencia no processo de evasão dessa população e em muito sofrimento por conta do abafamento e negligência quanto a tais violências no ambiente acadêmico.

De acordo com Mendes (2007), a ausência de um espaço público de fala na instituição inviabiliza a mobilização para construção de estratégias de transformação da organização do trabalho. As estudantes relataram a importância dos espaços públicos de fala, pois estes locais as permitem: a) relatar suas vivências sem que sejam deslegitimadas; b) encontrar representatividade de suas histórias e identidades e; c) receber apoio de estudantes negras e negros para lidar com os sofrimentos advindos de racismos e sexismos. Sendo assim, a mobilização coletiva das participantes deste estudo se atrela, pela utilização do espaço público de fala e cooperação, ao resgate emancipatório de si (Mendes, 2007), de forma que, a partir da reconstrução dos processos de subjetivação, elas reelaboram a sua presença, permanência e resistência na universidade:

Eu não participei efetivamente, claro, mas ver o estabelecimento do Quilombo ${ }^{2}$ foi uma coisa para mim assim revolucionária porque você sente

1 O nome das participantes foi trocado por mulheres negras brasileiras que inspiraram a escritora Jarid Arraes para escrever o livro: Heroínas Negras Brasileiras em 15 cordéis (Arraes, 2017)..

2 Quilombo é o Diretório Acadêmico Negro da Universidade de Brasília. Fundado pela co- 
que tem um espaço seu eu diria, tanto de palestra quanto de vivências. Até os eventos são mais pensados... umas coisas bem mínimas assim, mas que são efetivas. (Participante Esperança Garcia)

Quanto à classe que representa a rede de apoio, também nela se encontram fatores identificados como essenciais para que consigam se manter na graduação, tais como auxílio estudantil ou apoio financeiro da família, exemplificada pela fala da participante Esperança Garcia “A assistência estudantil... ajuda muito porque quando eu comecei [a trabalhar] no município eles não pagavam nem auxílio transporte... Mais da metade do nosso salário ficava de passagem.”

A classe "Ocupação de espaços" apresenta uma relação mais forte com as redes de suporte identificadas na Classe 1, uma vez os principais sofrimentos identificados são a sensação de não pertencimento e de exclusão e percepção de dificuldades relacionadas com a permanência na graduação, levando à busca de suporte. A constatação de que há um baixo número de estudantes negros na universidade reforça a sensação de exclusão e invisibilização. Essa constante ausência de pessoas negras em espaços acadêmicos pode colaborar com a normalização do pensamento de que tal lugar não pertence a estes estudantes. Ao mesmo tempo, é atribuída às pessoas negras a responsabilidade por tal fato (Oliveira, Meneghel \& Souza Bernardes, 2009), em um processo de negação do fator sócio-histórico-cultural do colonialismo e racismo presentes no Brasil. O relato a seguir, da participante Carolina Maria de Jesus, exemplifica a constatação de tais vivências: "Essa questão de [ser] negra... Na minha sala, acho que eu sou a única... É porque eu já estou acostumada desde sempre,... desde criança... a ser a única negra... Aí, ficava, tipo, normal, sabe?”

Além disso, as dificuldades apontadas pelas entrevistadas indicam que a permanência é sentida como sobrevivência. Resistir às cobranças e estigmas direcionadas às mulheres negras em espaços em que elas não são 
vistas como pertencentes é considerada uma luta cotidiana e necessária para sua carreira acadêmica e permanência nesse espaço. De acordo com a participante Zamciba Gaba:

Quando você se sobressai sobre qualquer aluno branco você é uma aluna negra que é uma boa aluna. Você não é uma boa aluna, você é uma boa aluna negra, então eu não esperava isso de você... E sempre eles estão esperando menos de você... Aí quando você se mostra um pessoa que realmente estuda, lê vários textos e tudo mais, 'Nossa! Você lê vários textos, você entende sobre isso' e quando você não sabe é tipo um demérito. Assim, nesse sentido, eu acho que esses apontamentos [que você leu e entendeu] eles são muito cruciais para carreira acadêmica de alguém ou para você conseguir sobreviver nesses espaços (Participante Zamciba Gaba)

O auxílio estudantil, apesar de ser considerado baixo, mostrou-se de suma importância para a permanência no caso de algumas entrevistadas. Este benefício é considerado, por elas, uma forma de suporte para realizar sua graduação, visto que é utilizado para diferentes demandas: cópias de textos das disciplinas, passagens de ônibus, alimentação, como mencionam as participantes Esperança Garcia "Por mais que seja burocrática [assistência estudantil] e tal, só o fato de você poder assim comer de graça, sei lá. Parece uma coisa mínima, mas ajuda muito." e Aqualtune "Às vezes você tem que estagiar porque você tem que complementar a renda e é tudo ao mesmo tempo"

Em todas as entrevistas é explícita uma grande dificuldade de passar pela graduação, considerando, entre outras questões, a pressão oriunda da quantidade de textos exigidos como leitura obrigatória, no caso dos cursos de ciências humanas e sociais. A carga imposta, além das outras atividades fora do meio acadêmico, resulta em sobrecarga para as estudantes, como declara a participante:

Mas esse semestre foi muito duro para mim. Como, tipo, eu peguei cinco matérias, uma monitoria e UnB idiomas e mais todo o peso do resto, assim, às vezes eu estava muito surtada eu só chorava... Eu já peguei matéria com professor de sociologia e ele: para estudar ciências sociais tem que estudar 10 horas [por dia], não pode ter família, não pode sair para se divertir, tem 
que saber ler em não sei quantos idiomas e tudo mais. E eu fiquei: não era trote, era real. De repente eu estava sentindo saudade da aula trote. (Participante Luísa Mahin)

Observa-se que, além das dificuldades já relatadas, as estudantes negras identificam micro racismos, tais como a ausência de autores negros nas ementas das disciplinas e falta de reconhecimento das diferenças raciais nos estudos, fator relevante as áreas de ciências sociais e humanas, conforme relatado:

Tem uma matéria, que é sociologia brasileira. E aí eu estava dando uma olhada na ementa não tem nenhum autor negro. Tipo, nenhum... E aí, eu me incomodo com a ausência dos textos [de autores negros] nas ementas... Você tem que dar um jeito de ler as pessoas que você quer ler, os autores negros para você, sei lá, fazer a sua pesquisa um dia, fazer uma série de coisas e ler todo mundo que é branco e ser bom nisso porque se você não for, não vai dar. (Participante Luísa Mahin)

A fala desta participante expõe um quadro parecido e anteriormente apontado por Nascimento (1978): "Falar em identidade negra numa universidade do país é o mesmo que provocar todas as iras do inferno, e constitui um difícil desafio aos raros universitários afro-brasileiros".

Tanto a ausência física de estudantes negros, quanto a ausência da produção intelectual deste povo são entendidas como uma forma de epistemicídio. Os autores acadêmicos negros e suas ideias não ocupam espaço no meio, ainda que o conhecimento destes seja relevante para a ciência (Carneiro, 2005). Para além da ausência do conhecimento negro, o epistemicídio é presente também no fato de que, em estudos sociais, a questão da racialidade não é considerada, invisibilizando ainda mais as particularidades dessa população. A identificação do epistemicídio elucida a relação das classes "Trajetória acadêmica" e "Percepções do racismo", conforme indicado na figura 1.

Ao analisar a Classe "Percepções do racismo", observa-se que sua relação com as três outras classes. As falas das participantes nesta classe apontam para o racismo explícito de colegas, professores e instituição, que se materializa na falta do reconhecimento e legitimação do próprio 
racismo que elas denunciam. Neste sentido, a questão de sofrer racismo na realidade de ser mulher permeia diferentes espaços (graduação, rede de suporte, família). No grupo das entrevistadas, uma maneira comum de lidar com a deslegitimação dos colegas brancos após denunciarem o racismo foi o próprio silenciamento. A fala da participante Aqualtune elucida este tipo de defesa:

Mas é a minha palavra contra a palavra de um professor e quando a gente fala: "ah não, tal argumento é racista, homofóbico, machista". A gente sempre escuta “ah não, mas você tem certeza?”. E é como se, naquele momento, a galera tirasse a sua base e deslegitimasse tudo que você demorou tanto tempo para construir. (Participante Aqualtune)

O silenciamento das estudantes negras é utilizado como forma de apagamento das questões por elas levantadas. Historicamente este mecanismo de silenciamento foi utilizado para a exclusão e controle social da população negra perante o estado.

Não sei, às vezes eu penso, "ah, deve ser coisa minha", isso [racismo] não existe, sabe? Sei lá, eu que quero ver dessa forma, às vezes, eu tô sendo muito... Não sei a palavra... Muito dura, sabe? Não sei, comigo, não sei, às vezes eu tô, como posso falar? Porque realmente é difícil. Tipo, eu to vendo aquilo dessa forma, mas não necessariamente é. (Participante Caroline Maria de Jesus)

Apesar de serem considerados privilégios, ingressar na faculdade e permanecer nela são processos contínuos de luta, tanto de forma individual como coletiva. Os processos de ingresso e permanência de negros na universidade pública possuem especificidades. O ingresso apresenta reflexos das lutas do movimento negro brasileiro para a inserção de cotas raciais nos vestibulares. Ao ocupar o espaço de estudante, o racismo permanece presente como epistemicídio e racismo institucional.

As entrevistadas abordaram também o sexismo como vivência presente na graduação, de forma que há concomitância dessas violências na trajetória de vida dessas estudantes. Nesse sentido, é evidente a consubstancialidade de gênero, raça e classe, reafirmando a impossibilidade de análise 
separada dessas questões. No entanto, observa-se uma predominância das questões raciais nessas falas, evidenciando que o racismo percebido por elas se estende também para os homens negros.

Essa predominância pode ser explicada a partir do contexto sócio-histórico-cultural brasileiro. A inserção da população negra no ensino superior se deu de forma tardia em relação à população branca. Segundo os dados da PNAD (Moehlecke, 2000), em 1987, o número de pessoas brancas, na faixa de idade entre 25 e 29 anos, que frequentaram ou concluíram o ensino superior foi, aproximadamente, 4 vezes maior que o número de negros. Especificamente, $12,2 \%$ da população branca contra 2,9\% da população negra (pardos e pretos). Conforme supracitado na introdução deste estudo, em 2017, 32,9\% da população branca com a idade entre 18 e 24 anos, frequenta o ensino superior, ao passo que 16,7\% é negra. Em relação ao gênero, 19,7\% dos homens frequentam o ensino superior, enquanto $26,8 \%$ das mulheres frequentam este espaço, sendo possível afirmar que, em relação ao gênero e a educação superior, o Brasil está caminhando, quantitativamente, para uma igualdade de acessos aos espaços acadêmicos.

Sob a ótica da psicodinâmica do trabalho, para as mulheres negras estudantes e participantes deste estudo, no trabalho de estudar estão envolvidas mais vivências de sofrimento que de prazer. Quando aparece, o prazer advém do reconhecimento intrafamiliar ao se tornar estudante de graduação, principalmente no caso da universidade pública. Elas se consideram privilegiadas, em comparação com a população negra brasileira e de classes sociais baixas, por terem acesso ao ensino superior. Esse sentimento de privilégio pode ser considerado reflexo do acesso tardio e dificultado da população negras a graduação. Tal processo foi representado nas falas das participantes, por exemplo no trecho do relato:

Meu avô falou que quando ele soube que eu estava fazendo graduação era como se ele tivesse vivendo de novo [...] e é uma coisa que me emociona muito. Reconhecer e ver a importância [...] para a vida dele. Ele vê isso [...], ele reviveu sim e eu vejo o quanto a questão racial realmente é importante nessa hora. Porque, sei lá, pro meu avô falar isso, quando o avô de outras pessoas já tem graduação, já é pós doutorado, já é isso, já é aquilo. Fazer graduação pra todo mundo de outras classes é normal. Pra gente, pessoas 
negras e de classe social baixa, ainda é um sonho, ainda mais numa federal. Você vê que ainda tem esse filtro: não basta ser superior tem que ser federal. Aí quando você está na federal o reconhecimento realmente é maior porque a gente sabe que é muito mais difícil. (Participante Esperança Garcia)

Como observado na fala, há uma valorização do reconhecimento dos pares familiares. Para a psicodinâmica do trabalho, o reconhecimento se configura como uma via de prazer para essas estudantes, uma vez que reforça sua identidade pessoal (Mendes, 2008). Porém, esse reconhecimento dos familiares não se configura, para a psicodinâmica do trabalho (Dejours, 2012) como reconhecimento no trabalho, mas sim como uma gratidão. Ainda que seja importante para este indivíduo, substituir o reconhecimento pela gratidão pode culminar em superinvestimento do trabalhador nesta relação, acarretando em esgotamento (Molinier, 2008). Esse reconhecimento percebido pelas participantes não é advindo da instituição, de forma que a posição de estudante é valorizada na população negra, inclusive pela baixa representatividade e pela histórica falta de acesso enquanto, nas instituições de ensino, o trabalho delas não é reconhecido. Para além disso, este trabalho, muitas vezes é dificultado ou impossibilitado, conforme identificado nas classes “Trajetórias acadêmicas" e "Percepção de racismos". Isso significa que, por mais que este reconhecimento dos pares seja um suporte para essas estudantes, o não reconhecimento do seu trabalho, bem como o epistemicídio, não permitem que ela ocupe este espaço de construção de saber, dificultando a mobilização subjetiva dessas mulheres.

A mobilização subjetiva é a possibilidade de transformar o sofrimento em prazer no trabalho, e estrutura-se por meio da utilização da cooperação e espaço público de fala (Ferreira \& Mendes, 2003). Os espaços públicos de fala, construídos pelos trabalhadores e reconhecidos pelos pares e hierarquia, caracteriza-se como espaço seguro para a formação e verbalização de ideias desses trabalhadores. A relação existente nesses espaços públicos é pautada pela cooperação desses participantes, uma vez que a segurança deste local é construída por meio das relações de confiança e solidariedade. Assim, a cooperação dentro destes espaços permite que as ideias e opiniões 
de cada trabalhador encontrem convergências, fortalecendo a identidade coletiva do grupo e sua diversidade. (Ferreira \& Mendes, 2003; Mendes, 1995).

A partir das falas das participantes, é possível identificar a mobilização subjetiva e coletiva delas por meio da utilização de espaços público de fala e cooperação. Ao criarem e utilizarem estes espaços, elas possuem ferramentas que dão conta do processo de transformação do sofrimento em prazer. Contudo, as possibilidades de mobilizações destas estudantes nos ambientes universitários são limitadas a espaços criados e frequentados por estudantes negros, pois nestes espaços há legitimação do sofrimento e reconhecimento das mazelas que as estruturas racistas acarretam na permanência destes corpos em ambientes acadêmicos. Ao sair destes espaços delimitados e ampliar o olhar institucional, foi observada a inexistência do reconhecimento da competência e do sofrimento das estudantes pelos pares e pela hierarquia, resquícios do mito da democracia racial. Sendo assim as estudantes esbarram em dificuldades de se mobilizar, pois a estrutura institucional não possibilita os devidos recursos para suscitar mobilizações, coletivas ou subjetivas.

Neste sentido, a mobilização coletiva entre estudantes negros fortalece a identidade individual e coletiva do grupo, o que proporciona um nível de reconhecimento suficiente que ressignifique a sua presença, permanência e resistência na universidade. No entanto, as barreiras identificadas como o epistemicídio e o não reconhecimento institucional dos sofrimentos dificultam a possibilidade de transformação do sofrimento advindo trabalho de estudar em prazer. Entretanto, esse processo de transformação do sofrimento é revisitado pela possibilidade de reescreverem suas histórias (ao encontrarem força nos coletivos de estudantes negros), que foram predeterminadas pelo seu corpo negro (o racismo percebido na universidade e as limitações exercidas por ele), ao ocuparem um lugar que, por séculos, foi negado (espaços acadêmicos). 


\section{CONSIDERAÇÕES FINAIS}

A impossibilidade de se valer da liberdade para transformar e aperfeiçoar o seu espaço de trabalho é uma fonte de sofrimento que acarreta em frustração, medo e impotência (Martins, 2007). Tais aspectos se fazem presentes nas entrevistas, quando essas estudantes pontuam as dificuldades que elas sentem na graduação. Para além da falta de espaço, o não reconhecimento da contribuição dessa população também interfere na saúde desse trabalho. Assim, essas mulheres não conseguem lançar mão de sua inteligência prática ou possuem espaço público de fala para transformar o sofrimento advindo da situação de trabalho em prazer.

A fala dessas mulheres sobres suas vivências acadêmicas elucidam um aspecto ainda não vencido no Brasil: o racismo como estrutura de poder advinda de uma categoria social excludente e assassina de corpos e mentes negras em diferentes espaços. O número relativamente baixo de estudos sobre o preconceito racial no campo da psicologia (Sacco, Couto \& Kohler, 2016) é um reflexo dessa estrutura, reafirmando o mito da democracia racial. Neste sentido, identificar e denunciar o preconceito racial sofrido por essas estudantes, contribui para a ampliação dos estudos relativos à população negra. Ainda que incipientes, os estudos sobre relações raciais e preconceito mostram o potencial de uma psicologia engajada com a sociedade, evidenciando a importância e urgência de mais estudos exploratórios, assim como a criação de ações afirmativas para a transformação e ressignificação desses espaços. Tais ações são relevantes no contexto histórico e político brasileiro para o caminhar de uma sociedade mais igualitária tanto nos acessos aos direitos garantidos constitucionalmente, como na permanência em tais espaços, conquistados por lutas ainda recentes.

\section{REFERÊNCIAS}

Arraes, J. (2017). Heroínas negras brasileiras em 15 cordéis. São Paulo: Pólen

Bento, M. A. S. (1995). Mulher negra no mercado de trabalho. Estudos feministas, 3(2), 479-488 
Bourdieu, Pierre, (1998a). A escola conservadora: as desigualdades frente à escola e à cultura. In: M. A., Nogueira, A. Catani, Afrânio (orgs.) Escritos de educação: P. Bourdieu. Petrópolis: Vozes. Cap. 2, p. 39-64. Brasil. Instituto Brasileiro de Geografia e Estatística (2010). Censo demográfico 2010: educação e deslocamento: resultados da amostra. Recuperado de https://biblioteca.ibge.gov.br/visualizacao/ periodicos/545/cd_2010_educacao_e_deslocamento.pdfBrasil. Instituto Brasileiro de Geografia e Estatística (2017) PNAD Contínua - Educação. Recuperado de https://biblioteca.ibge.gov. br/visualizacao/livros/liv101576_informativo.pdf

Carneiro, A. S. (2005). A construção do outro como não-ser como fundamento do ser. (Tese de Doutorado). Universidade de São Paulo, São Paulo.

Carneiro, A. S. (2011). Racismo, sexismo e desigualdade no Brasil. São Paulo: Selo negro.

Camargo, B. V. \& Justo, A. M. (2013). IRAMUTEQ: um software gratuito para análise de dados textuais. Temas em Psicologia, 21(2), 513-518. Davis, A. (2016). Mulheres, raça e classe. São Paulo: Boitempo Dejours, C. (2004). Subjetividade, trabalho e ação. Production, 14(3), 27-34. Dejours, C. (2012). Trabalho vivo volume 2: Trabalho e Emancipação. Brasília, Paralelo 15.

Dejours, C. (2016). A banalização da injustiça social (7a ed.). Rio de Janeiro: Editora Fundação Getúlio Vargas

Ferreira, M. C \& Mendes, A. M. (2003) Trabalho e riscos de adoecimento: $O$ caso dos auditores-fiscais da Previdência Social brasileira. Brasília: Edições Ler, Pensar e Agir

Gonzalez, L. (1984). Racismo e sexismo na cultura brasileira. Ciências sociais hoje, 2, 223-244.

Guimarães, A. S. A. (2016). Sociologia e natureza: classes, raça e sexos. In A. R. P. Abreu, H. Hirata \& M. R. Lombardi (Org.). Gênero e trabalho no Brasil e na França. pp. 27-36. São Paulo: Boitempo

Kergoat, D. (2016). O Cuidado e a imbricação das relações sociais. In A. R. P. Abreu, H. Hirata \& M. R. Lombardi (Org.). Gênero e trabalho no Brasil e na França pp. 17-26. São Paulo: Boitempo 
Martins, S. R. (2007). Subjetividade e adoecimento por DORTS em trabalhadores de um banco público de Santa Catarina. In A. M. Mendes (Org.). Psicodinâmica do trabalho: teoria, método e pesquisas, 229-254.

Mendes, A. M. (1995). Aspectos psicodinâmicos da relação homem-trabalho: as contribuições de C. Dejours. Psicologia: Ciência e Profissão, 15(13), 34-38.

Mendes, A. M. (2007). Da psicodinâmica à psicopatologia do trabalho. Psicodinâmica do trabalho: teoria, método e pesquisas. São Paulo: Casa do Psicólogo.

Mendes, A. M. (2008). Prazer, reconhecimento e transformação do sofrimento no trabalho. Trabalho e saúde: o sujeito entre emancipação e servidão, 2, 13-25.

Moehlecke, S. (2000). Propostas de Ações Afirmativas no Brasil: o acesso da população negra ao ensino superior. (Dissertação de Mestrado). Universidade de São Paulo, São Paulo.

Molinier, P. O trabalho e a psique: uma introdução à psicodinâmica do trabalho. Distrito Federal: Paralelo 15.

Nascimento, A. (1978). O genocídio do negro brasileiro: processo de um racismo mascarado. Rio de Janeiro: Paz e Terra.

Oliveira, M. L., Meneghel, S. N. \& de Souza Bernardes, J. (2009). Modos de subjetivação de mulheres negras: efeitos da discriminação racial. Psicologia \& Sociedade, 21(2). 266-274.

Queiroz, D. M. \& dos Santos, C. M. (2016). As mulheres negras brasileiras e o acesso à educação superior. Revista da FAEEBA-Educação $e$ Contemporaneidade, 25(45). 71-87

Ratinaud, P. (2009). IRAMUTEQ: Interface de $R$ pour les Analyses Multidimensionnelles de Textes et de Questionnaires [programa de computador]. Recuperado de http://www.iramuteq.org. 18/08/2018

Reichman, R. (1995). A Mulher Negra Brasileira: um retrato. Revista Estudos Feministas. 3(2)496-505

Sacco, A. M., Couto, M. P. P. \& Koller, S. H. (2016). Revisão sistemática de estudos da psicologia brasileira sobre preconceito racial. Temas em Psicologia. 24(1), 233-250. 
Santos, B. S. \& Meneses, M. P. (Org.). (2010). Epistemologias do Sul. São Paulo: Cortez.

Santos, H. R. A. F. (2017). A revolução não será televisonada (!?): o caso comparado da TV pública no Brasil e na Argentina. (Tese de Doutorado). Universidade de Brasília, Brasília.

Woleck, A. (2002). O trabalho, a ocupação e o emprego: Uma perspectiva histórica. Revista de Divulgação Técnico-científica do Instituto Catarinense de Pós-Graduação, 1, 33-39.

Xavier, E. C. \& Fontoura, G. M. D. (2013). Negras Minas: o sentido do trabalho para as mulheres negras. identidade!, 18(3), 425-440.

Zanello, V. (2018) Saúde mental, gênero e dispositivos: cultura e processos de subjetivação. Curitiba: Appris. 